\title{
Inter-Annual Variability of Water Exchange between the Azov Sea and the Sivash Bay through the Tonky Strait
}

\author{
E. S. Eremina ${ }^{1, *}$, V. P. Evstigneev ${ }^{2,3}$ \\ ${ }^{1}$ Marine Hydrophysical Institute of RAS, Sevastopol, Russian Federation \\ ${ }^{2}$ Sevastopol State University, Sevastopol, Russian Federation \\ ${ }^{3}$ Sevastopol Center for Hydrometeorology and Environmental Monitoring, Sevastopol, \\ Russian Federation \\ *shchurova88@gmail.com
}

Purpose. The work is aimed at studying the components' intra- and inter-annual variability in the water exchange between the Sivash Bay and the Sea of Azov through the Tonky Strait at the current climatic period based on the empirical conversion schemes and using the hydrometeorological observation data obtained at the nearby stations.

Methods and Results. Using the data on the sea level, and the wind direction and speed, the runoffs of the Azov Sea and the Sivash Bay waters in the Tonky Strait during 1966-2013 are calculated by two methods developed by Slatinsky Yu.G. in 1969 and Raskin L.G. in 1992. Predominance of the Azov currents over the Sivash ones is revealed. Seasonal and long-term dynamics of the runoff values in the strait are given based on the monthly average and annual average data. The data on the wind regime variability in the Genichesk region, and the sea level at the Genichesk meteorological station and at the Chongarsky bridge meteorological post are cited.

Conclusions. The calculations show that the average annual inflow of the Azov waters through the Tonky Strait varies within the wide range $0.3 \mathrm{~km}^{3}-1.18 \mathrm{~km}^{3}$, and the outflow of the Sivash waters constitutes on average $0.26 \mathrm{~km}^{3}$ per year. Difference between the water inflow and outflow in the strait is characterized by high inter-annual variability. Over the whole period under study, it amounted on average up to $0.45 \mathrm{~km}^{3}$. In the components' spectrum of water exchange between the Sivash Bay and the Azov Sea, distinguished are the $\sim 4$ year fluctuations of the Sivash waters outflow from the bay, and the 3 and 5-6 year fluctuations of the Azov Sea waters inflow to the Sivash Bay. Multi-year variability of the Sivash water outflow with the 4 year periodicity is conditioned by the same precipitation amount periodicity over the Sivash Bay.

Keywords: water balance, water exchange, sea level, Tonky Strait, Sivash, Sea of Azov.

Acknowledgements: the work was carried out within the framework of the state task on theme No. 0827-2019-0004 "Complex interdisciplinary studies of oceanological processes that determine functioning and evolution of ecosystems of the coastal zones of the Black and Azov seas". The investigation of V. P. Evstigneev was supported by the Russian Foundation for Basic Research within the framework of project No. 19-05-00803.

For citation: Eremina, E.S. and Evstigneev, V.P., 2020. Inter-Annual Variability of Water Exchange between the Azov Sea and the Sivash Bay through the Tonky Strait. Physical Oceanography, [e-journal] 27(5), pp. 489-500. doi:10.22449/1573-160X-2020-5-489-500

DOI: $10.22449 / 1573-160 X-2020-5-489-500$

(C) E. S. Eremina, V. P. Evstigneev, 2020

(C) Physical Oceanography, 2020

\section{Introduction}

Shelf zones, estuarine areas, gulfs and bays are of great scientific interest among researchers due to the fact that the ecosystems functioning in them are the most productive and most sensitive to climatic changes and anthropogenic pressure [1-2]. Hydro-ecological studies of hypersaline water bodies, including estuaries with limited water exchange with the sea, are of particular interest [3-5]. As a rule, such a regime of water bodies is formed in arid zones of a hot climate 
[3]. However, hypersaline water bodies (lakes, estuaries, bays) also exist in regions with a temperate climate. The conditions for the formation of high salinity level in them change either with the seasons, which is typical for the estuaries of the Mediterranean Sea [6], or throughout the year due to the weakened inflow of freshened water from the adjacent sea or fresh water sources (rivers).

It is the second type of mechanism for the hyperhaline regime formation, together with shallowness, that is characteristic of the Sivash lagoon-type bay. One of the income items of its balance until 2014 was the flow of drainage and waste water from agricultural fields in the amount of about 630 million $\mathrm{m}^{3}$ per year [7-8], due to operation of the North Crimean Canal (NCC), built in 1971. After the NCC closure in 2014 and, as a consequence, a change in the fresh water inflow regime, a global restructuring of the ecosystem in the Sivash Bay occur. This transformation takes place against the background of natural variability of the water balance main components, one of which is water exchange with the Sea of Azov.

The Sivash Bay water area is included in the list of wetlands of international importance, is a unique biotope and is distinguished by high biodiversity. Due to high salinity of the Sivash waters and the inexhaustible reserves of salts, the region has prospects for the chemical industry development: in 1960s the South Sivash was considered as a powerful raw material base for the production of brine magnesium oxide and bromine. The Sivash region also has significant balneological potential: reserves of iodine-bromine and sulphide mineral waters have been approved, and there are sources of valuable silt sulphide mud in the bays. The Sivash Bay resources are determined by a special water balance, and the variability of the balance components affects the established natural balance.

The study of the processes occurring in the Sivash Bay under current conditions, including the metamorphization of the bay waters, is of practical importance and is of scientific interest. In addition, the variability of water and salt balance in this basin can potentially be parameterized by simple mathematical models due to its shallowness and semi-enclosureness.

The exchange of waters between the bay and the sea is carried out through the Genichesk Strait, as well as by the seepage of the Sea of Azov waters through the Arabat Spit body. In [9], an analysis of the Eastern Sivash area satellite images is presented. In this analysis a number of features of both water temperature and optical properties along the Arabat Spit were revealed. Moreover, the temperature anomalies, as a rule, manifested themselves in the form of local regions (the jets directed off the coast); in the optical range, in this region, the zones with reduced scattering (turbidity) are observed. According to A.M. Ponizovskiy [10], the inflow of the Sea of Azov waters by filtering through the bar is insignificant: for the Southern Sivash $-7360 \mathrm{~m}^{3}$ per day, or 115 thousand $\mathrm{m}^{3}$ per year.

The Genichesk Strait is currently subdivided into two branches - the Tonky and Promoina Straits. Until 1970, the water exchange through the Promoina Strait was almost absent; at present, the water flow through it is, presumably, insignificant due to its shallowness and morphometric structure features [11]. However, it is impossible to estimate the real water exchange in the strait, since the field measurements in the channel are absent. 
Basically, water exchange between the Sea of Azov and the Sivash Bay is carried out through the Tonkiy Strait, which is about $5 \mathrm{~km}$ long, 70 to $180 \mathrm{~m}$ wide and up to $5 \mathrm{~m}$ deep (at the exit from the strait to the Sivash Bay the depth is less than $1 \mathrm{~m}$ ). The water exchange dynamics in the strait depends on many factors: the Sea of Azov level in the area of the strait, direction, speed and duration of winds, changes in the level of the bay itself.

There are few works on the estimations of water exchange through the Tonkiy Strait [11-13]. At present, the water exchange between the Sivash Bay and the Sea of Azov is being studied based on generalization of episodic measurements of currents and discharges in the Tonkiy Strait in the section near MS Genichesk (see, for example, [11]). The results of such a study may have certain limitations in terms of the representativeness of the generalized hydrological indicators for different seasons of the year. Due to the conditions limiting the carrying out of hydrometric works in the strait (the presence of ice, storm conditions, etc.), the number of measurements is unevenly distributed from season to season. So, according to data from [11], when summarizing the research results for 1939-2008, the total number of measurements in the winter period was an order of magnitude smaller than, for example, in the summer and autumn seasons.

The question of the representativeness of the regime estimates obtained on the basis of only episodic measurements is also relevant in the study of the interannual variability of water exchange through the strait. Thus, the most abundant data is the period 1964-1981, while since 1975 there have been no observations in the winter season, and after 1990 they have become extremely few in number [11]. However, the regime assessment of changes in the water exchange value between the Sivash Bay and the Sea of Azov on the intra- and interannual scales should be carried out on the basis of homogeneous data series, for example, meteorological ones, which can be used to recalculate the water inflow through the Tonkiy Strait.

In the works of Yu.G. Slatinsky and L.G. Raskin [12, 13], similar calculation methods, developed on the basis of data from parallel hydrometric measurements and standard hydrometeorological observations at MS Genichesk and/or MP Chongarsky Bridge stations, are presented.

The purpose of this work is to study intra- and interannual variability of the components of water exchange between the Sivash Bay and the Sea of Azov through the Tonkiy Strait in the modern climatic period based on empirical recalculation schemes using hydrometeorological observations at nearby stations.

\section{Research materials and method}

In this work, we analyzed the water discharge in the Tonkiy Strait in 1966-2013, calculated based on observations of the sea level, wind direction and speed at the sea coastal stations of MS Genichesk and MP Chongarsky Bridge in the Sivash Bay (Fig. 1).

The calculation of the discharge rates of the Azov and Sivash waters through the Tonkiy Strait was carried out using two methods: of Yu.G. Slatinsky [12] and L.G. Raskin [13]. The method of Yu.G. Slatinsky (SM) was developed before the start of the NCC operation for calculating water exchange in the Tonkiy Strait. Thus, on the basis of a large amount of measurement data carried out in 
1961-1964, the dependence of the direction and velocities of currents in the Tonkiy Strait on the water level height in Genichesk under different wind conditions was established. Empirical connection curves were plotted for different wind conditions:

$$
Q=f(H),
$$

where $Q$ is water discharge through the cross-section of the strait, $\mathrm{m}^{3} / \mathrm{s} ; H$ is the level height in Genichesk, $\mathrm{cm}$. The instantaneous water discharges obtained by this method are reduced to an average daily indicator and converted into volumetric flow units. The main disadvantage of the method is the lack of parametrization of the NCC influence on the water exchange in the strait. This influence manifested itself in a decrease in the difference between the levels of the Sea of Azov and the Sivash Bay.

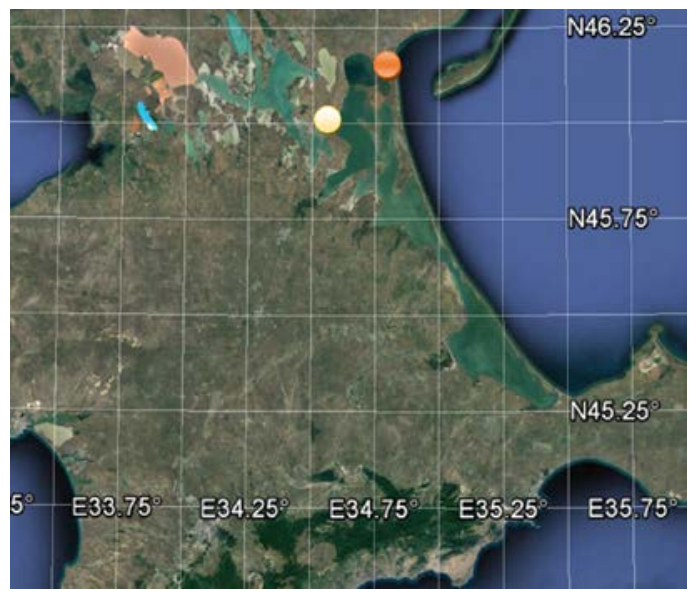

F i g. 1. Map-scheme of the Sivash Bay showing locations of the Genichesk MS (red circle) and the Chongarsky bridge MP (yellow circle) stations

In order to eliminate this disadvantage, based on the data obtained during the SOGOIN expeditions in the Tonkiy Strait in 1986-1988 (the period of active operation of the canal), L.G. Raskin developed a methodology (RM) that takes into account the level difference between the Sivash Bay and the Tonkiy Strait (at the entrance from the Sea of Azov) [13]. On the basis of this method, he studied the mechanism of the formation of currents in the strait, established a relationship between the measured average current velocity on the central vertical of the stream gauge and the average current velocity over the entire cross section of the strait in the same section line. The average current velocity along the strait cross section was calculated as a result of dividing the instantaneous discharge rate by the stream gauge area. The measurements and the methods are described in more detail in [13]. The empirical constraint equation obtained as a result of research has the form

$$
V_{\mathrm{av}}=0.014+0.76 V_{\mathrm{cv}},
$$

where $V_{\mathrm{av}}$ is an average velocity of current at the stream gauge, $\mathrm{m} / \mathrm{s} ; V_{\mathrm{cv}}$ is an average velocity of current at the central vertical, $\mathrm{m} / \mathrm{s}$. 
In order to calculate the water exchange, taking into account possible changes in the freshwater component of the Sivash water balance, a correlation analysis between the strait current velocities obtained from field data, the difference in the sea levels at the hydrometeorological station Genichesk MS and at MP Chongarsky Bridge in the bay and the wind velocity projection on the strait axis was carried out. As a result of this study, L.G. Raskin obtained significant regression dependence in the form of the following equation

$$
V_{\mathrm{cv}}=(1.1 \Delta H+2.53 W-1.42) 10^{-2},
$$

where $\Delta H$ is a difference of levels at MS Genichesk and at MP Chongarsky Bridge, $\mathrm{cm}$; $W$ is a vector of wind velocity projection on the strait axis, $\mathrm{m} / \mathrm{s}$.

Using equations (1), (2), and (3) as applied to the observational data at two stations, the water exchange value and direction in the Tonkiy Strait for 1966-2013 were calculated in this work. The amount of water exchange is expressed in cubic kilometers. For recalculating the average current velocity into the runoff volume, it is required to know the gauge station cross-sectional area, which, in its turn, depends on the sea level in the strait. According to [13, p. 27], the variation in the cross-sectional area $S$ depending on the level variation in Genichesk $H$ can be represented as

$$
S=265+0.675(H-470)
$$

A climatological estimation of water exchange taking into account this dependence, as well as an estimation of the accompanying hydrometeorological regime conditions, against which the intensity of water exchange vary, are given in this work.

\section{Characteristics of hydrometeorologic regime in the Sivash Bay area}

The Sea of Azov is located in the southern part of the temperate zone, and its climate is formed under effect of large-scale synoptic processes: the development of the Siberian anticyclone wedge in the cold season and the Azores anticyclone in summer [14]. Wind conditions in the Sivash Bay area generally correspond to the regime of the entire Sea of Azov basin. The regime is characterized by the predominance of winds from the eastern quarter, especially during the cold period (from October to April). A more detailed analysis of the wind regime was carried out using data from Genichesk station for 1966-2013. According to the results of this analysis, the general trends in the distribution of wind characteristics are as follows.

The average annual frequency of prevailing easterly winds is $20 \%$, westerly $13 \%$, in summer, easterly and westerly winds are observed with almost the same frequency - 15 and 13\%, respectively (Fig. 2, a). During the cold period of the year, the easterly winds have the highest occurrence frequency, which reaches $23.5 \%$.

The wind velocity in Genichesk area has a pronounced annual variation. The maximum wind activity falls on November - March, the minimum - on the summer season, when the frequency of calm and weak winds with of up to $5 \mathrm{~m} / \mathrm{s}$ velocity increases. In 1966-2013 Calms were encountered in 15.3\% of cases on average per year, the frequency of winds with a up to $5 \mathrm{~m} / \mathrm{s}$ velocity was $62.2 \%$, 
moderate winds $(6-11 \mathrm{~m} / \mathrm{s})$ accounted for $18.3 \%$ in total, strong and stormy winds were characteristic mainly for the winter months and met with $4.1 \%$ frequency.

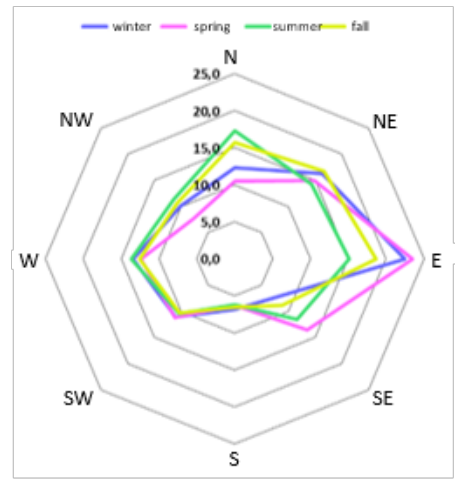

a

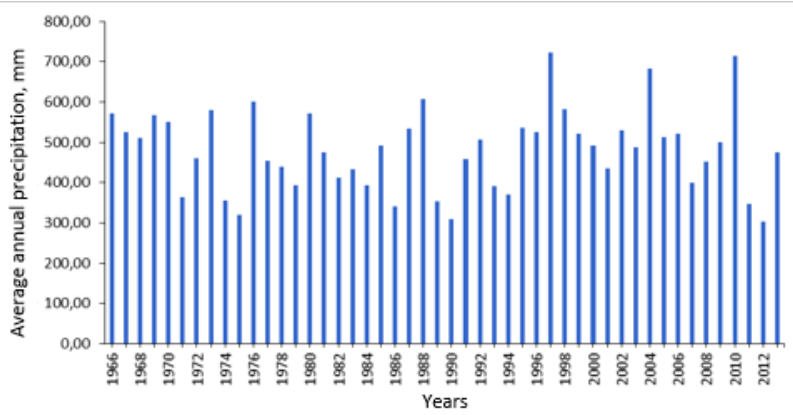

b

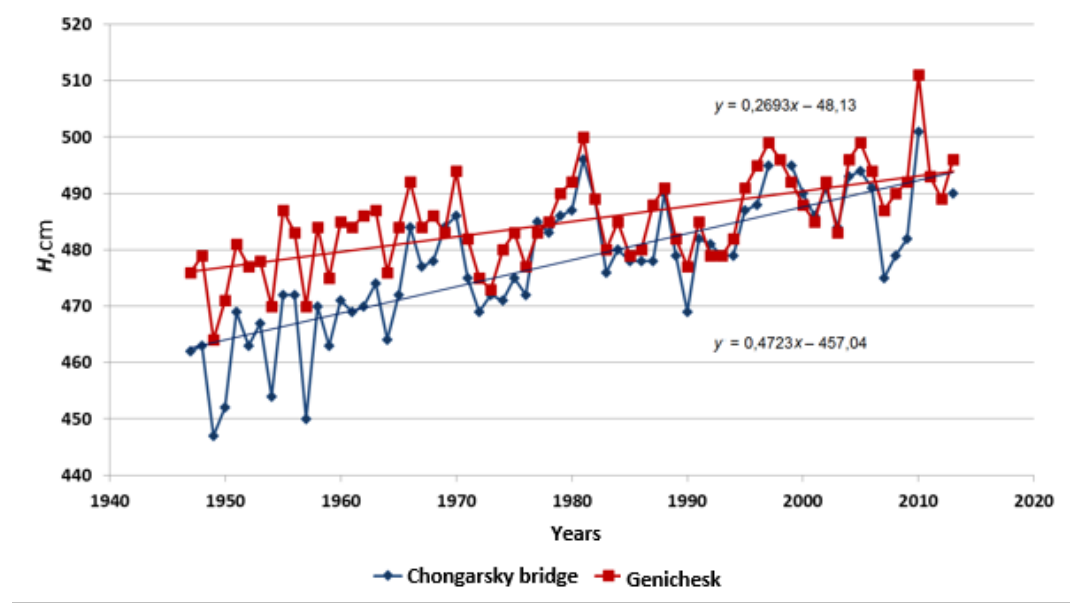

$C$

F i g. 2. Hydrometeorological regime characteristic in the Tonky Strait region based on the data from the Genichesk MS and the Chongarsky bridge MP for 1966-2013: seasonal repeatability of the wind directions at the Genichesk MS $(a)$; graph of variation of the annual precipitation amount over the Sivash Bay based on [16] (b); multi-year variation of the sea level average annual values at the Genichesk MS and the Chongarsky bridge MP for 1947-2013 (c)

In the long-term level variation at the stations on the Sea of Azov coast, the fluctuations with periods of 2-3 years and 25-30 years are distinguished [15]. Seasonal dynamics of the Sea of Azov level is determined by intra-annual variability of the water balance components and wind conditions. The maximums in the annual variation of the mean monthly sea level values $(486-493 \mathrm{~cm}$ at the station in Genichesk) are observed in March - June, when the river runoff reaches its maximum. From June to October, the sea level drops due to a decrease in atmospheric precipitation, river runoff and an increase in evaporation. By October, the monthly average values of the level decrease to $471 \mathrm{~cm}$. With an increase in 
the contribution of the fresh water balance components - atmospheric precipitation and surge processes - the sea level in Genichesk increases from November to May.

Synoptic level fluctuations are determined by surge processes and are characterized by significant amplitudes: at the station in Genichesk, the level rises, more than $2 \mathrm{~m}$ higher than the average long-term values [15], occur.

Until 1969, the difference in sea levels in the Sivash Bay and in the Genichesk area was more or less stable and averaged $13.5 \mathrm{~cm}$. With the beginning of the canal operation and the influx of fresh water large volumes from agricultural land, the water level at MP Chongarsky Bridge significantly increased, and the level difference decreased, on average, to $3.8 \mathrm{~cm}$. In some years, the level at the MP Chongarskiy Brodge exceeded the level at MS Genichesk (Fig. 2, c). In general, at both stations a tendency towards an increase in the water level was observed.

The difference in sea levels at the ends of the Tonkiy Strait, and hence the intensity of water exchange between two basins, depends on the water inflow into the Sivash Bay with atmospheric precipitation. Precipitation regime over the Sivash Bay in 1966-2010 is considered in detail in [16]. The volume of water supplied with precipitation has a pronounced seasonal variation and reaches its maximum in the warm half of the year from May to August, reaching an average volume of $0.14-0.18 \mathrm{~km}^{3} /$ month. The minimum amount of precipitation falls on the cold season with the minimums in April $\left(0.1 \mathrm{~km}^{3} / \mathrm{month}\right)$ and October $\left(0.09 \mathrm{~km}^{3} / \mathrm{month}\right)$. Average long-term value of the annual amount of precipitation falling on the bay surface was $1.45 \mathrm{~km}^{3} /$ month [16]. For the calculation period 1966-2013 their minimum annual amount was recorded in 1971, 1974, 1990 and 2012. The rainiest years were 1997, 2004, 2010. (Fig. 2, b). In the series of annual precipitation amounts over the Sivash Bay, fluctuations with characteristic periods of 4 and 6-7 years were found out (Fig. 3, b). Spectral analysis was performed using the standard Daniell method [17], the spectrum was calculated using the Tukey spectral window with an effective number of freedom degrees of 6.5. Before carrying out the spectral analysis, the polynomial trend of the third order was preliminarily removed from the time series.

Precipitation is the most important input component of the Sivash Bay, which affects the fresh water content in it and, as a consequence, the excess of its level relative to the zero level surface. When comparing the variation graphs in Fig. 2, $b$ and 2, $c$, it can be seen that the maximums of the annual precipitation amounts over the Sivash Bay coincide with the maximums of the mean sea level at MP Chongarsky Bridge. Spectral peaks with periods of 4 and 6-7 years are found in the spectrum of sea level variability at MP Chongarsky Bridge (see Fig. 3, b). The relationship between fluctuations in precipitation and sea level at the indicated periods is characterized by a relatively high coherence level -0.5 and 0.6 , respectively (see Fig. 3, b).

On the contrary, at MS Genichesk, located in the Tonkiy Strait from the Sea of Azov side, such coordination of fluctuations is not observed: in Fig. 3, $b$, $a$ separate peak is traced at $4-5$ years period of fluctuations, however, the sea level variability in Genichesk is mainly concentrated at periods of 7-20 years. On the spectrum of sea level coherence with precipitation amount, one most pronounced peak corresponds to a period of 8 years. 


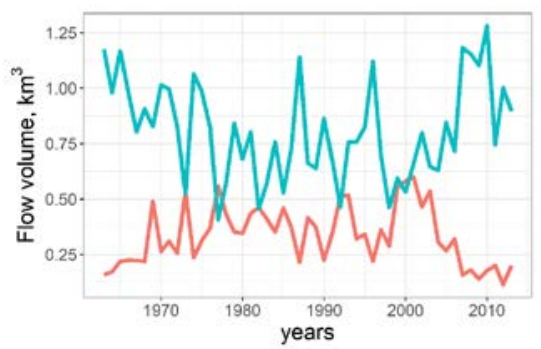

$a$
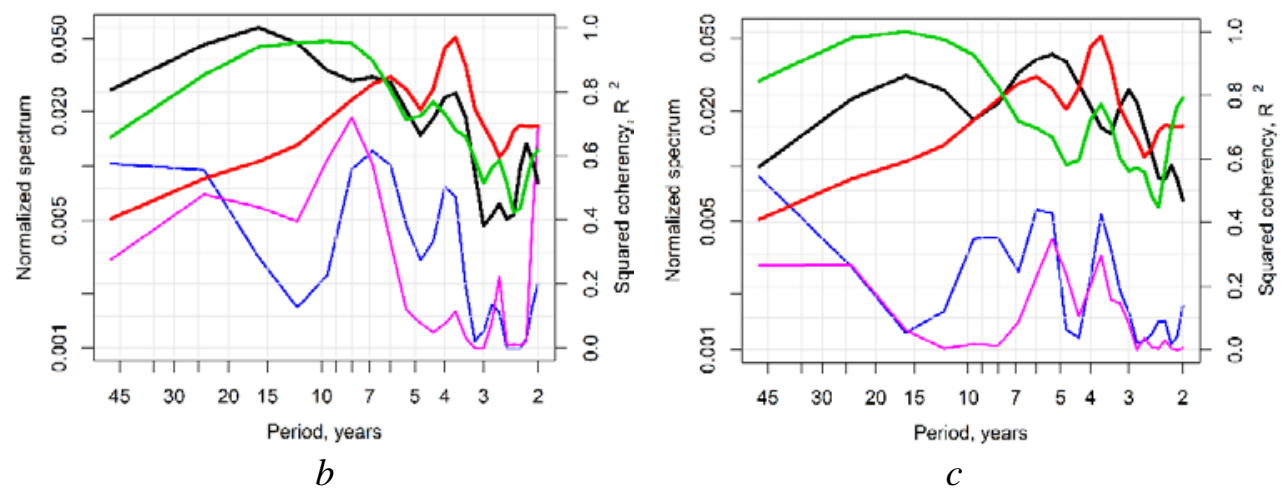

F i g. 3. Characteristics of water exchange through the Tonky Strait: $a$ - the Sivash (red line) and the Azov Sea (blue line) runoff volumes in the Tonky Strait in 1966-2013; $b$ - spectra of variability of the sea level at the Genichesk MS (green line) and at the Chongarsky bridge MP (black line), and of the annual precipitation amount over the bay (red line); coherence spectra between the series "sea level at the Chongarsky bridge MP - precipitation amount" (blue line) and "sea level at the Genichesk MS - precipitation amount" (lilac line); $c$ - variability spectra of the Sivash water outflow from the bay (green line), the Azov Sea water inflow to the bay (black line) and of the annual precipitation amount over the bay (red line), and also the coherence spectra "outflow - precipitation" (blue line) and "inflow - precipitation" (lilac line)

Despite the different conditions for the formation of interannual sea level variability in the Sivash Bay and the Sea of Azov, the difference in sea levels in these two basins determines the intensity of water exchange between them through the Tonkiy Strait.

\section{Characteristics of water exchange in the Tonkiy Strait}

The regime of currents in the Tonkiy Strait is determined by the sea level difference, which determines the slope of the level surface in the strait towards the Sivash, and the wind regime. According to the data of expeditionary observations in 1980s, the Sea of Azov currents were observed in 63\% of cases, the Sivash currents were observed in 35\% and mixed currents were observed only in $1 \%$ of cases [11, 13]. At the same time, according to the data from [12], approximately $55-57 \%$ of all cases of the Sea of Azov currents are observed at calm or weak unstable winds of all directions and are caused by the difference in sea levels at the ends of the strait, as well as only $20 \%$ is associated with surge winds of the eastern direction. The Sivash currents arise in $90-92 \%$ of all cases at strong westerly winds.

In this work, the monthly and annual mean values of the Sea of Azov and the Sivash currents runoff in the Tonkiy Strait were calculated by SM and RM. 
According to the calculation results, the predominance of the Sea of Azov waters runoff over the Sivash waters remains throughout the studied period. Water exchange in the Tonkiy Strait has seasonal characteristics: the maximum inflow of the Sea of Azov waters into the Sivash Bay falls on April - August (Fig. 3, a) and coincides in time with the period of the highest level rise in the Sea of Azov. The minimum inflow into the Sivash is observed in September and in the winter months, during the development of ice phenomena in the sea. The Sivash currents are mainly observed in March - April and in the autumn season with a maximum in October ${ }^{1}$.

Such a picture of intra-annual distribution of the Azov-Sivash waters' runoffs reflects the wind regime seasonal features. It was noted above that westerly winds, surging the Sivash waters, are less common in autumn, while the easterly winds prevail in winter. Water exchange between the Sivash and the Sea of Azov is mainly determined by fluctuations in the sea level surface and corresponds to the seasonal level dynamics.

The annual mean inflow of the Sea of Azov waters into the Sivash in 1966-2013, calculated by SM, was $1.75 \mathrm{~km}^{3}$, and the outflow of the Sivash waters $-0.08 \mathrm{~km}^{3}$. The data of the inflow obtained by us are in good agreement with the estimates of Yu.G. Slatinsky for 1961-1966 period. According to his calculations, an average of $1.7 \mathrm{~km}^{3}$ of the Sea of Azov waters entered the Sivash, but the Sivash component of water exchange in our calculations turned out to be significantly lower ${ }^{1}$. Obviously, this is due to the underestimation of the fresh water component contribution (drainage runoff) to the Sivash Bay balance, as a result of which occurred such significant deviations in the estimates of real water exchange. In this regard, it is more expedient to use RM method.

The calculation according to RM allows taking into account the level variations in the bay, which was reflected in the results of assessing the outflow of the Sivash waters into the Sea of Azov: it amounted to $0.26 \mathrm{~km}^{3}$ on average per year (table). The average annual inflow of the Sea of Azov waters varied within a wide range from 0.3 to $1.18 \mathrm{~km}^{3}$ (Fig. 3, a).

Monthly average values of the Azov Sea water inflow and the Sivash Bay water outflow $\left(\mathrm{km}^{3}\right)$ in the Tonky Strait in 1966-2013, calculated by two methods

\begin{tabular}{|c|c|c|c|c|c|c|c|c|c|c|c|c|c|}
\hline \multirow{2}{*}{ Component } & \multicolumn{12}{|c|}{ Months } & \multirow{2}{*}{ Eyear } \\
\hline & 1 & 2 & 3 & 4 & 5 & 6 & 7 & 8 & 9 & 10 & 11 & 12 & \\
\hline \multicolumn{14}{|c|}{ Calculated by the Raskin method } \\
\hline Outflow & 0.018 & 0.014 & 0.023 & 0.021 & 0.013 & 0.012 & 0.012 & 0.013 & 0.028 & 0.039 & 0.041 & 0.034 & 0.265 \\
\hline$\underline{\text { Inflow }}$ & 0.046 & 0.022 & 0.046 & 0.059 & 0.072 & 0.065 & 0.078 & 0.076 & 0.061 & 0.065 & 0.065 & 0.068 & 0.718 \\
\hline \multicolumn{14}{|c|}{ Calculated by the Slatinsky method } \\
\hline Outflow & 0.005 & 0.002 & 0.003 & 0.004 & 0.001 & 0.003 & 0.004 & 0.004 & 0.014 & 0.021 & 0.019 & 0.012 & 0.088 \\
\hline Inflow & 0.112 & 0.068 & 0.163 & 0.202 & 0.225 & 0.196 & 0.181 & 0.152 & 0.116 & 0.119 & 0.135 & 0.141 & 1.665 \\
\hline
\end{tabular}

1 Eremina, E.S. and Evstigneev, V.P., 2019. [Estimates of the Azov-Sivash Waters Runoffs in the Tonkiy Strait]. In: MHI, 2019. Seas of Russia: Fundamental And Applied Research: abstracts of the AllRussian scientific conference, Sevastopol, September 23-28, 2019. Sevastopol: MHI, 2019, pp. 195. Available at: http://mhi-ras.ru/assets/files/morya_rossii-2019_tezisy.pdf\#1 [Accessed: 09 August 2020]. 
Calculations showed a decrease in the inflow of the Sea of Azov waters in 1976-2006: from 1963 to 1976, on average $0.81 \mathrm{~km}^{3}$ came from the Sea of Azov to the Sivash. With the beginning of the NCC operation the inflow decreased by, on average, $0.2 \mathrm{~km}^{3}$. Since 2007, there has been an increase in the Sea of Azov water inflow and a decrease in the outflow from the Sivash (Fig. 3,a), which is due to a sharp difference in levels between the bay and the sea in these years (Fig. 2, c). Probably, the level difference is associated with a decrease in the water inflow from the NCC, since there was no noticeable increase in the amount of precipitation over the Sivash Bay in these years (Fig. 2, b). The difference between the water inflow and outflow in the strait is characterized by high interannual variability. On average, for the entire study period the difference was $0.45 \mathrm{~km}^{3}$, in some years, when the sea level at MP Chongarsky Bridge was equal to the level at MS Genichesk, the water exchange components were equal, and when it was higher the outflow from the Sivash exceeded the inflow from the sea. The most likely cause for such an increase in the Sivash Bay level was the NCC operation.

In the spectrum of the Sivash waters outflow variability (see Fig. 3, c), fluctuations with a period of about 4 years were found. The same period is the main peak of the precipitation variability spectral density over the Sivash Bay. On the coherence spectrum this period corresponds to the coherence of 0.4 , although a secondary peak of coherence for periods of 5-6 years is pointed out. The causes for the decrease in the coherence between fluctuations are the effect of wind velocity over the Tonkiy Strait and the difference in the levels in the bay and in the Sea of Azov on the water exchange intensity. To a greater extent, the level variability in the MS Genichesk area is determined by the dynamics of variation in the Sea of Azov level. In particular, the superposition of various affecting factors leads to a shift in the peaks in the spectrum of water inflow from the Sea of Azov for the periods of 3 and 5-6 years. At the same time, weak coherence between the tributary of the Sea of Azov waters and precipitation over the Sivash Bay is manifested at intervals of $4-5$ years.

\section{Conclusions}

In this work we used two empirical methods, developed for different hydrological regimes of the Sivash Bay, for calculating water exchange in the Tonkiy Strait. Analysis of the obtained water discharge rates in 1966-2013 showed that SM does not take into account the increase in the bay level during the canal operation, therefore, from the 1970s for calculating the water exchange components in the Tonkiy Strait, it is advisable to use the RM, in which the calculation is based on the equation of dependence on the level difference between the Sea of Azov and the Sivash Bay. The method for calculating water discharge in the Tonkiy Strait based on data from standard hydrometeorological observations was adapted and implemented in software.

Calculations showed that the average annual inflow of the Sea of Azov waters varies within wide limits from 0.3 to $1.18 \mathrm{~km}^{3}$, the Sivash Bay waters outflow averages $0.26 \mathrm{~km}^{3}$ per year. The difference between the water inflow and outflow in the strait is characterized by high interannual variability. On average, for the entire study period, it was $0.45 \mathrm{~km}^{3}$. In the spectrum of components of water exchange between the Sivash Bay and the Sea of Azov, fluctuations with $\sim 4$ years 
period for the outflow of the Sivash waters from the bay and with periods of 3 and 5-6 years for the inflow of the Sea of Azov waters into the Sivash Bay are distinguished. The long-term variability of the Sivash waters outflow with a period of 4 years is due to a similar variability in the amount of precipitation over the Sivash Bay. Interannual variability of precipitation amount determines the interannual variability of sea level in the Sivash Bay.

The obtained runoff values can be used in retrospective water balance calculations for the Sivash Bay in 1966-2013. After 2014, no data has been received from the observation point in Genichesk (Ukraine), MP Chongarsky Bridge does not function. This makes it impossible to estimate the Azov-Sivash water exchange based on indirect measurements at meteorological stations and on the basis of empirical methods.

\section{REFERENCES}

1. Waycott, M., Duarte, C.M., Carruthers, T.J.B., Orth, R.J., Dennison, W.C., Olyarnik, S., Calladine, A., Fourqurean, J.W., Heck Jr., K.L., Hughes, A.R., Kendrick, G.A., Kenworthy, W.J., Short, F.T. and Williams, S.L., 2009. Accelerating Loss of Seagrasses across the Globe Threatens Coastal Ecosystems. Proceedings of the National Academy of Sciences, 106(30), pp. 12377-12381. https://doi.org/10.1073/pnas.0905620106

2. Carstensen, J., Klais, R. and Cloern, J.E., 2015. Phytoplankton Blooms in Estuarine and Coastal Waters: Seasonal Patterns and Key Species. Estuarine, Coastal and Shelf Science, 162, pp. 98-109. http://dx.doi.org/10.1016/j.ecss.2015.05.005

3. Wooldridge, T.H., Adams, J.B. and Fernandes, M., 2016. Biotic Responses to Extreme Hypersalinity in an Arid Zone Estuary, South Africa. South African Journal of Botany, 107, pp. 160-169. http://dx.doi.org/10.1016/j.sajb.2016.05.004

4. Prazukin, A.V., Anufriieva, E.V. and Shadrin, N.V., 2018. Cladophora Mats in a Crimean Hypersaline Lake: Structure, Dynamics, and Inhabiting Animals. Journal of Oceanology and Limnology, 36(6), pp. 1930-1940. https://doi.org/10.1007/s00343-018-7313-4

5. Potter, I.C., Chuwen, B.M., Hoeksema, S.D. and Elliott, M., 2010. The Concept of an Estuary: A Definition That Incorporates Systems Which Can Become Closed to the Ocean and Hypersaline. Estuarine, Coastal and Shelf Science, 87(3), pp. 497-500. doi:10.1016/j.ecss.2010.01.021

6. Largier, J.L., Hollibaugh, J.T. and Smith, S.V., 1997. Seasonally Hypersaline Estuaries in Mediterranean-climate Regions. Estuarine, Coastal and Shelf Science, 45(6), pp. 789-797. https://doi.org/10.1006/ecss.1997.0279

7. Sovga, E.E., Eryemina, E.S. and Khmara, T.V., 2018. Water Balance in the Sivash Bay as a Result of Variability of the Natural-Climatic and Anthropogenic Factors. Physical Oceanography, 25(1), pp. 67-76. doi:10.22449/1573-160X-2018-1-67-76

8. Kostyushina, V.A. and Fesenko, G.V., eds., 2007. Sivash Region: a Brief Socioeconomic Overview. Kiev: Wetlands International Black Sea Progr., 178 p. (in Russian).

9. Shchurova, E.S., Stanichnaya, R.R. and Stanichnuy, S.V., 2016. Using Satellite Data to Study the Current State of the Sivash Bay. Ecological Safety of Coastal and Shelf Zones of the Sea, (3), pp. 61-64 (in Russian).

10. Ponizovskiy, A.M., 1965. [Salt Resources of Crimea]. Simferopol: Crimea, 163 p. (in Russian).

11. Dyakov, N.N. and Belogudov, A.A., 2015. Water Exchange of the Gulf Sivash with the Sea of Azov through the Strait Genichesk (Thin). In: SOI, 2015. Proceedings of N.N. Zubov State Oceanographic Institute. Moscow, 2015. Issue 216, pp. 240-253 (in Russian).

12. Slatinskiy, Y.G., 1969. [About Waters Exchange between the Sivash and the Sea of Azov through the Tonky Strait]. Collection of Works of the Basin Hydrometeorological Observatory of the Black and Azov Seas, (7), pp. 38-54 (in Russian). 
13. Raskin, L.G, 1992. About Water Exchange through the Thin Strait. In: SOI, 2015. Proceedings of N.N. Zubov State Oceanographic Institute. Moscow, 2015. Issue 205, pp. 2131 (in Russian).

14. Polonsky, A., Evstigneev, V., Naumova, V. and Voskresenskaya E., 2014. Low-Frequency Variability of Storms in the Northern Black Sea and Associated Processes in the OceanAtmosphere System. Regional Environmental Change, 14(5), pp. 1861-1871. https://doi.org/10.1007/s10113-013-0546-z

15. Ilyin, Y.P., Fomin, V.V., Dyakov, N.N. and Horbach, S.B., 2000. Hydrometeorological Conditions of the Ukrainian Seas. Volume 1: Sea of Azov. Sevastopol: ECOSI-Hydrophysics, 402 p.

16. Evstigneev, V.P. and Eremina, E.S., 2019. Calculation of Precipitation over the Sivash Bay. Ecological Safety of Coastal and Shelf Zones of the Sea, (2), pp. 19-29. doi:10.22449/24135577-2019-2-19-29 (in Russian).

17. Brockwell, P.J. and Davis, R.A., 1991. Time Series: Theory and Methods. Springer, 580 p. doi:10.1007/978-1-4419-0320-4

About the authors:

Ekaterina S. Eremina - Junior Research Associate, Marine Hydrophysical Institute of RAS (2 Kapitanskaya St., 299011, Sevastopol, Russian Federation), SPIN-code: 5891-9884, ORCID ID: 0000-0002-5596-2691, ResearcherID: E-8676-2018, shchurova88@gmail.com

Vladislav P. Evstigneev - Senior Research Associate, Sevastopol State University (53 Universitetskaya St., 299053, Seavstopol, Russian Federation), Head of Sevastopol CHEM, SPINcode: 8739-5204, ORCID ID: 0000-0003-3064-2613, ResearcherID: G-1894-2014, Scopus Author ID: 12544785600, vald_e@rambler.ru

Contribution of the co-authors:

Ekaterina S. Eremina - processing and description of research results; analysis and preparation of initial conclusions; preparation of an initial version of the paper text

Vladislav P. Evstigneev - adaptation of methods, development and debugging of a computer program for solving a problem, computer implementation of algorithms; revision of the text

All the authors have read and approved the final manuscript.

The authors declare that they have no conflict of interest. 